Supporting Information for

\title{
Ultrafine Co-doped NiO nanoparticles decorated on carbon nanotubes improving the electrochemical performance and cycling stability of $\mathrm{Li}-\mathrm{CO}_{2}$ batteries
}

\footnotetext{
Xu Xiao ${ }^{\mathrm{a}}$, Zhuojun Zhang ${ }^{\mathrm{a}}$, Wentao $\mathrm{Yu}^{\mathrm{a}}$, Wenxu Shang ${ }^{\mathrm{a}}$, Yanyi Ma ${ }^{\mathrm{a}}$, Xingbao Zhu ${ }^{\mathrm{b}}$, Peng Tan ${ }^{\mathrm{a}^{*}}$

${ }^{a}$ Department of Thermal Science and Energy Engineering, University of Science and Technology of China (USTC), Hefei 230026, Anhui, China

b School of Physics, Harbin Institute of Technology, Harbin 150080, Heilongjiang, China

*Corresponding author.

E-mail address: zhuxingbao008@163.com (Xingbao Zhu)

E-mail address: pengtan@ustc.edu.cn (Peng Tan)
} 


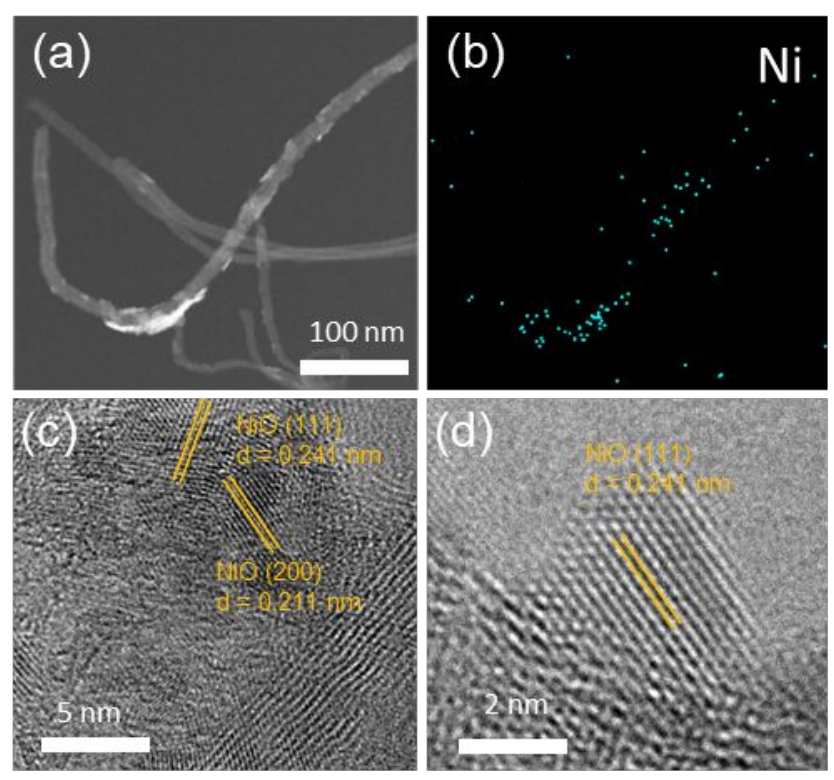

Figure S1 Morphology characterization of NiO/CNT (a) TEM image; (b) EDS mapping of Ni element; and (c-d) HRTEM images.
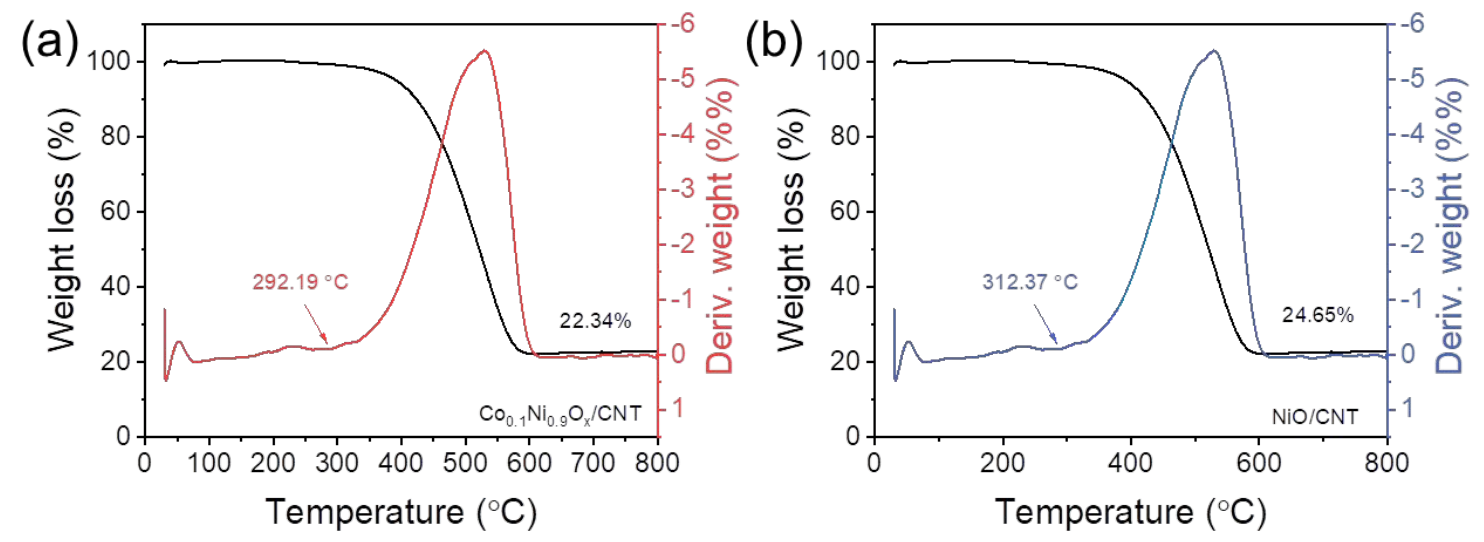

Figure S2 TG-DTG curves of (a) $\mathrm{Co}_{0.1} \mathrm{Ni}_{0.9} \mathrm{O}_{\mathrm{x}} / \mathrm{CNT}$ and (b) $\mathrm{NiO} / \mathrm{CNT}$. 
(a)

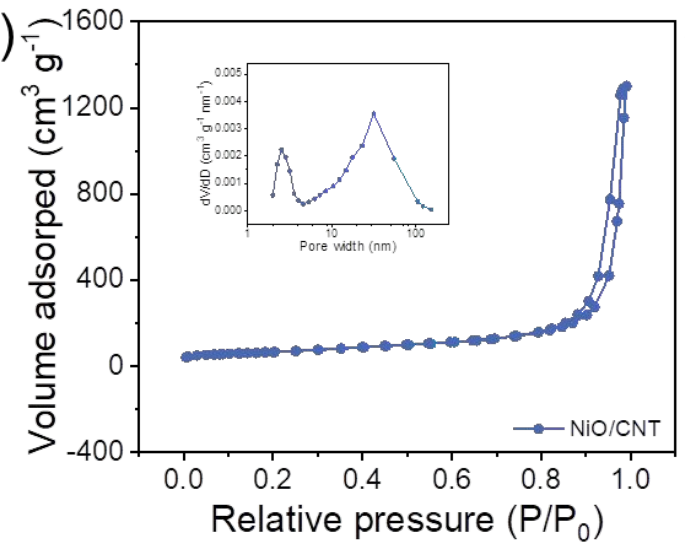

(b)

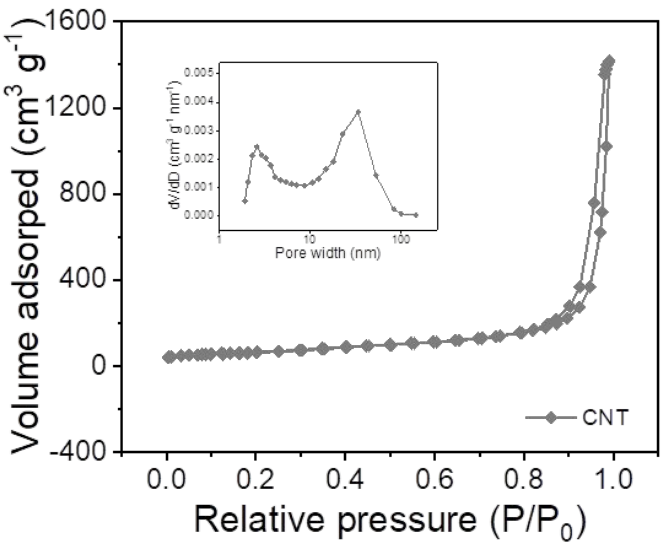

Figure S3 Nitrogen adsorption-desorption isotherm, and the inset shows the pore-size distribution of (a) NiO/CNT and (b) CNT.

(a)

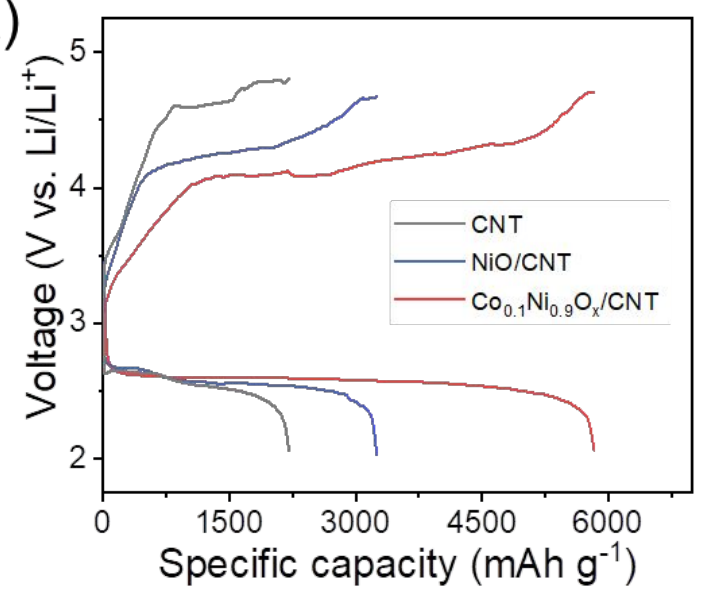

(b)

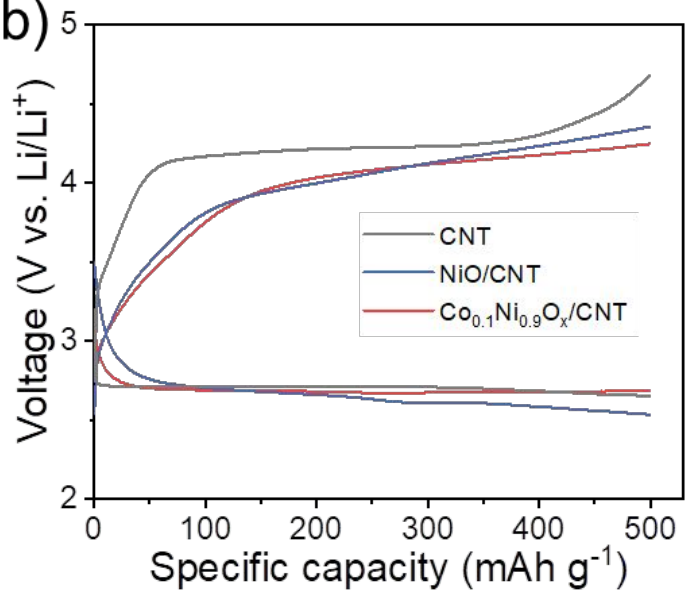

Figure S4 Electrochemical performance of Li-CO2 batteries with different electrode materials at the current density of $100 \mathrm{~mA} \mathrm{~g}^{-1}$ : (a) full discharge-charge voltage profiles; (b) discharge-charge voltage profiles with a cutoff capacity of $500 \mathrm{mAh} \mathrm{g}^{-1}$. 

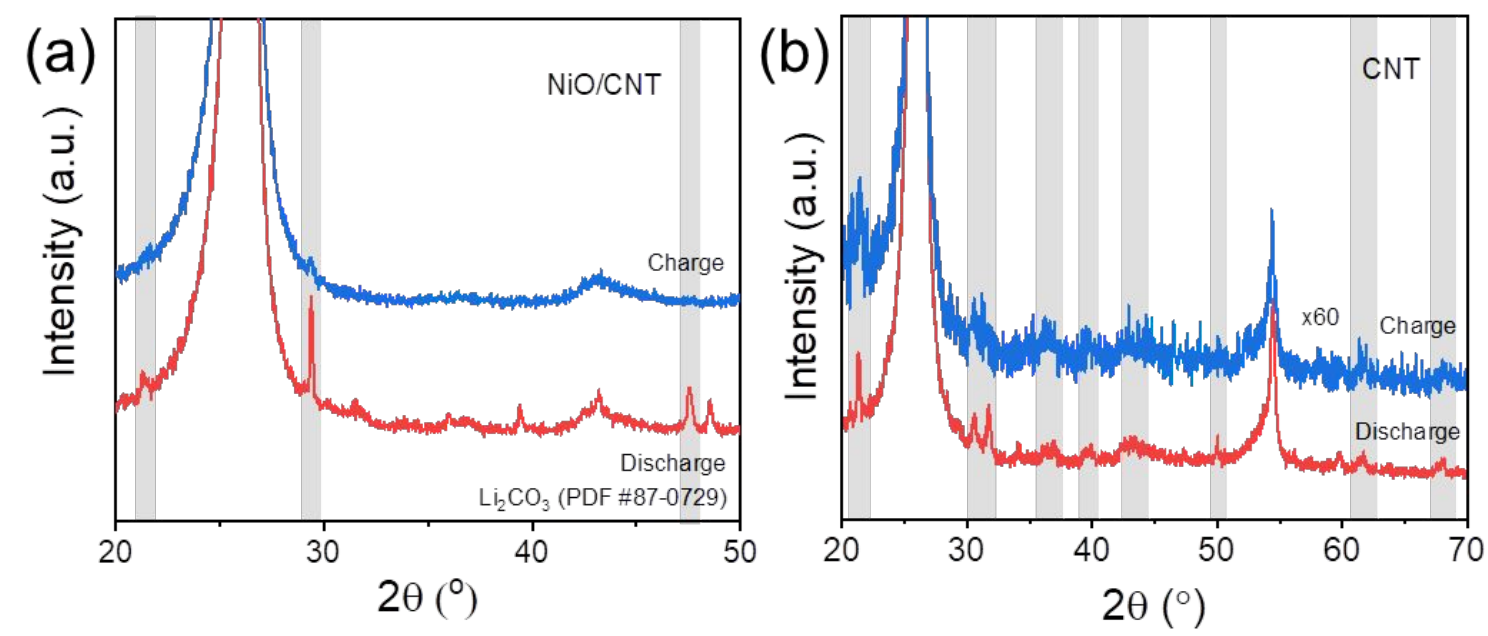

Figure S5 XRD patterns after first cycled with $500 \mathrm{mAh} \mathrm{g}^{-1}$ at $100 \mathrm{~mA} \mathrm{~g}^{-1}$ of (a) $\mathrm{NiO} / \mathrm{CNT}$ and (b) CNT.

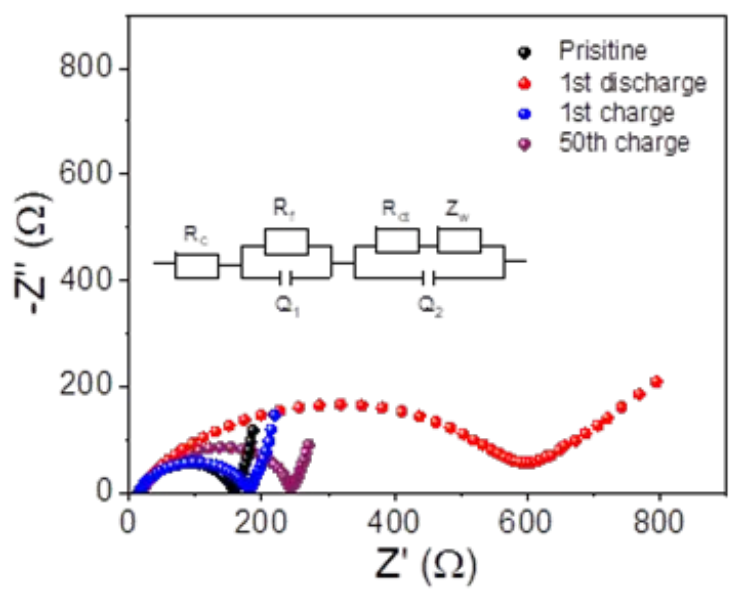

Figure S6 EIS results of the battery made of $\mathrm{Co}_{0.1} \mathrm{Ni}_{0.9} \mathrm{O}_{\mathrm{x}} / \mathrm{CNT}$ electrode at different state. After 1st and even 50th charge, the slight increase of impedance is attributed to the formation SEI film on the surface of lithium electrode through $\mathrm{CO}_{2}$ and side products crossover, as reported in literature. ${ }^{1}$ 
Table S1 XPS results

\begin{tabular}{cccc}
\hline Sample & molar ratio (\%) $/ \mathrm{NiO}+\mathrm{Ni}(\mathbf{O H})_{2}$ & $\mathbf{O}_{\text {latt }} /\left(\mathbf{O}_{\text {ads }}+\mathbf{O}_{\text {latt }}\right)$ & $\mathbf{C o} /(\mathbf{C o}+\mathbf{N i})$ \\
\hline $\mathrm{NiO} / \mathrm{CNT}$ & 48.76 & 33.61 & \\
$\mathrm{Co}_{0.1} \mathrm{Ni}_{0.9} \mathrm{O}_{\mathrm{x}} / \mathrm{CNT}$ & 39.51 & 18.37 & 15.01 \\
\hline
\end{tabular}

*Oads contains oxygen-deficient regions $\left(\mathrm{O}_{\mathrm{ads} 1}\right)$ and hydroxyl groups $\left(\mathrm{O}_{\mathrm{ads} 2}\right)$.

Table S2 The specific surface area and pore volume of prepared materials

\begin{tabular}{ccc}
\hline Sample & Surface area $\left(\mathbf{m}^{\mathbf{2}} \mathbf{g}^{-\mathbf{1}}\right)$ & Pore volume $\left(\mathbf{c m}^{\mathbf{3}} \mathbf{g}^{-\mathbf{1}}\right)$ \\
\hline $\mathrm{CNT}$ & 297.4 & 2.19 \\
$\mathrm{NiO} / \mathrm{CNT}$ & 291.8 & 2.01 \\
$\mathrm{Co}_{0.1} \mathrm{Ni}_{0.9} \mathrm{O}_{\mathrm{x}} / \mathrm{CNT}$ & 284.3 & 1.65 \\
\hline
\end{tabular}


Table S3 Performance comparison of NiO-based materials in $\mathrm{Li}-\mathrm{CO}_{2}$ batteries.

\begin{tabular}{ccccccc}
\hline Cathode & $\begin{array}{c}\text { Current } \\
\left(\mathrm{mA} \mathrm{cm}^{-2}\right)\end{array}$ & $\begin{array}{c}\text { Overpotential } \\
(\mathrm{V})\end{array}$ & $\begin{array}{c}\text { Cycle capacity } \\
\left(\mathrm{mAh} \mathrm{cm}^{-2}\right)\end{array}$ & $\begin{array}{c}\text { Cycle } \\
\text { number }\end{array}$ & $\begin{array}{c}\text { Areal capacity } \\
\left(\mathrm{mAh} \mathrm{cm}^{-2}\right)\end{array}$ & Ref. \\
\hline $\mathrm{NiO} / \mathrm{CC}$ & 0.011 & 1.3 & 0.055 & 33 & 0.055 & 2 \\
$\mathrm{NiO} / \mathrm{CT}$ & 0.035 & 1.5 & 0.35 & 67 & 3.362 & 3 \\
$\mathrm{NiO} \mathrm{NPs}$ & 0.04 & 1.7 & 0.4 & 80 & 3.322 & 4 \\
$\mathrm{NiO} \mathrm{NFs}$ & 0.04 & 1.6 & 0.4 & 134 & 4.515 & 4 \\
$\mathrm{NiO} / \mathrm{CNT}$ & $50 \mathrm{~mA} \mathrm{~g}^{-1}$ & 1.6 & $1000 \mathrm{~mA} \mathrm{~g}^{-1}$ & 45 & $9000 \mathrm{mAh} \mathrm{g}^{-1}$ & 5 \\
$\mathrm{NiO} / \mathrm{CNT}$ & 0.102 & 1.4 & 0.51 & 32 & 2.6 & this work \\
\hline
\end{tabular}

The performance of NiO-based $\mathrm{Li}-\mathrm{CO}_{2}$ system in the reported works is summarized. The specific current and capacity $\left(\mathrm{mA} \mathrm{g}^{-1}\right.$ and $\left.\mathrm{mAh} \mathrm{g}^{-1}\right)$ are hard to be compared due the different weights of catalysts on the electrode. From the battery performance facing the actual application, the absolute areal current and capacity are adopted in the following comparison. As shown in Table S3, the current $\left(\mathrm{mA} \mathrm{cm}^{-2}\right)$ in this work is twice to tenfold larger than those in others. Usually, the current increases doubled and then the capacity decreases doubled in $\mathrm{Li}-\mathrm{CO}_{2}$ batteries. ${ }^{6-8}$ While in this work, although the current density is more than $0.1 \mathrm{~mA} \mathrm{~cm}^{-2}$, the areal capacity is still as high as $2.6 \mathrm{mAh} \mathrm{cm}^{-2}$. Besides, the overpotential is as low as $1.4 \mathrm{~V}$. Further, the capacity used for cycling is high (accounting for $\sim 20 \%$ of the total capacity), while the battery can be operated stably. Therefore, the discharge capacity and the cycle performance in this work are excellent. 


\section{References}

(1) Chen, K.; Huang, G.; Ma, J. L.; Wang, J.; Yang, D. Y.; Yang, X. Y.; Yu, Y.; Zhang, X. B. The Stabilization Effect of $\mathrm{CO}_{2}$ in Lithium-Oxygen $/ \mathrm{CO}_{2}$ Batteries. Angew. Chemie - Int. Ed. 2020, 59 (38), 16661-16667.

(2) Zheng, R.; Shu, C.; Li, J.; Hu, A.; Chen, N.; Li, M.; Long, J. Oxygen Vacancy Engineering of Vertically Aligned $\mathrm{NiO}$ Nanosheets for Effective $\mathrm{CO}_{2}$ Reduction and Capture in Li-CO 2 Battery. Electrochim. Acta 2021, 383, 138359.

(3) Wang, C.; Lu, Y.; Lu, S.; Ma, S.; Zhu, X.; Li, Z.; Liu, Q. Boosting Li-CO 2 Battery Performances by Engineering Oxygen Vacancy on NiO Nanosheets Array. J. Power Sources 2021, 495 (March), 229782.

(4) Lu, S.; Shang, Y.; Ma, S.; Lu, Y.; Liu, Q. C.; Li, Z. J. Porous NiO Nanofibers as an Efficient Electrocatalyst towards Long Cycling Life Rechargeable Li$\mathrm{CO}_{2}$ Batteries. Electrochim. Acta 2019, 319, 958-965.

(5) Zhang, X.; Wang, C.; Li, H.; Wang, X. G.; Chen, Y. N.; Xie, Z.; Zhou, Z. High Performance $\mathrm{Li}-\mathrm{CO}_{2}$ Batteries with NiO-CNT Cathodes. J. Mater. Chem. A 2018, 6 (6), 2792-2796.

(6) Li, J.; Qin, X.; Li, X.; Miao, X.; Huang, S.; Lv, J. Boron-Doped Carbon Microspheres as a New Catalyst for Rechargeable Li- $\mathrm{CO}_{2}$ Batteries. Fullerenes Nanotub. Carbon Nanostructures 2020, 28 (8), 680-685.

(7) Zhang, Z.; Zhang, Q.; Chen, Y.; Bao, J.; Zhou, X.; Xie, Z.; Wei, J.; Zhou, Z. The First Introduction of Graphene to Rechargeable Li- $\mathrm{CO}_{2}$ Batteries. Angew. Chemie - Int. Ed. 2015, 54 (22), 6550-6553.

(8) Ge, B.; Sun, Y.; Guo, J.; Yan, X.; Fernandez, C.; Peng, Q. A Co-Doped $\mathrm{MnO}_{2}$ Catalyst for $\mathrm{Li}-\mathrm{CO}_{2}$ Batteries with Low Overpotential and Ultrahigh Cyclability. Small 2019, 1902220, 1-8. 